\section{DIARY}

BACD/BDTA Roadshow

CosmETHICS: ethical cosmetic

dentistry for everyday practice

Date/location: 19 January 2012

(London)

23 February 2012 (Manchester)

22 March 2012 (Bristol)

24 May 2012 (Belfast)

12 July 2012 (Birmingham)

20 September 2012 (Edinburgh)

25 October 2012 (Liverpool)

Telephone: 02082418526

Email: suzy@bacd.com

British Dental Conference

and Exhibition 2012

Date: 26-28 April 2012

Venue: Manchester Central

Convention Complex

www.bda.org/conference

11th Congress of the European

Academy of Paediatric Dentistry

A Crossroads of Knowledge,

Innovation and Expertise

Date: 24-27 May 2012

Venue: Convention Centre,

Strasbourg, France

www.eapd2011.eu

S4S Introduction to Occlusal

Splints for the GDP

Date: 25 May 2012

Location: London

Telephone: 01142500176

www.s4sdental.com

\section{BDA Oral Cancer course}

Date: 29 June 2012

Venue: BDA, London

Telephone: 02075634590

www.bda.org/training

British Dental Bleaching

Society AGM

Date: 26 July 2012

Venue: House of Commons

Email:info@bdbs.co.uk

www.bdbs.co.uk

\section{BDA BULLETIN}

The Department of Health minister Earl Howe has been confirmed to speak at this year's British Dental Conference and Exhibition in Manchester.

Addressing the conference on the morning of Friday 27 April, Earl Howe will provide delegates with an insight into the Government's vision for the future of dental services. Delegates will have the opportunity to put questions to the Minister, with topics such as the new dental contract and the commissioning of dental services likely to top the agenda.
The BDA has warned that proposed cuts to Health Service dentistry in Northern Ireland are wholly unacceptable and would be catastrophic for practitioners' capacity to provide Health Service care. Dr Peter Crooks, Chair of the BDA's Northern Ireland Dental Practice Committee, has written to the Department of Health, Social Services and Public Safety to warn the cuts it is proposing to dental services would exacerbate the funding problems already confronting dental practices, and represent a fundamental change to the contract under which dentists work. The proposals also appear to jeopardise the long-running negotiations for a new dental contract. Proposed cuts include changes to eligibility for the higher rate of practice allowance, the removal of commitment payments, a scaling back of Health Service treatment to a core service, and the introduction of a time bar of 12 months on scaling and polishing.

\title{
LESS CHEWING LINKED TO DENTAL CROWDING
}

Researchers at the School of Anthropology and Conservation at the University of Kent studying 11 globally distributed populations have found that as humans shifted from a hunter-gatherer to an agricultural lifestyle, their jawbones became shorter and broader. This could explain the relatively high incidence of dental crowding and dental misalignment in modern populations.

The relationship between global mandibular shape variation and subsistence economy was tested, while controlling for the potentially confounding effects of shared population history, geography and climate.
The results of the study ${ }^{1}$ support notions that a decrease in masticatory stress among agriculturalists caused the mandible to grow and develop differently. This also explains why there is often a mismatch between the size of the lower face and the dentition.

1. von Cramon-Taubadel N. Global human mandibular variation reflects differences in agricultural and hunter-gatherer subsistence strategies. Proc Natl Acad Sci USA 2011; 108: 19546-19551.

\section{GDC ANNOUNCEMENTS}

- New research commissioned by the GDC has found that $94 \%$ of patients are confident in the dental treatment they are receiving and 95\% are satisfied. In the last 12 months $65 \%$ of those asked had visited a dentist and $70 \%$ were very or fairly confident that if they needed to make a complaint it would be resolved fairly, whether by the GDC or another appropriate body. Sixty-eight percent are confident that the GDC is an effective regulator.

- The GDC's next registrant event is being held at the Bristol Marriott Hotel, 2 Lower Castle Street, Bristol on 26 January 2012. Dental professionals from in and around Bristol are invited to come along to find out about how the GDC's work affects them. Attendees will also be able to take part in one of two workshops: one on the review of the GDC's Standards for dental professionals and one on the responsibilities of being a dental professional. Early booking for this free event (with two hours of CPD) is advised at www. gdc-uk.org/GDCcalendar.

- A similar registrant event will also take place in Northern Ireland on 2 February 2012. Dental professionals in the Derry/ Londonderry area are asked to come along to the Waterfoot Hotel in Waterside and book at the website address given above.

\section{SCHEME WILL RECRUIT OVER 100 APPRENTICE DENTAL NURSES}

A major initiative to recruit over 100 apprentice dental nurses throughout England in the next 18 months has been launched by national dental corporate Genix Healthcare Limited.

With 22 clinics across England and further plans for expansion, Genix Healthcare will increase its workforce by almost one third through the apprentice programme with an investment of around £250,000.
The Genix Healthcare

Apprenticeship Programme, run in partnership with City Training Services, will provide comprehensive training support for candidates for as long as three years taking them through to achieve a level three qualification. After an induction candidates will work in a practice, fully supervised by experienced staff, and have the opportunity to progress to an Advanced Apprenticeship in Dental Nursing (level 3). Further training through the "Genix Academy' offers potential for candidates to take further education. 